\title{
Prevention of peritoneal adhesion using a bacterial cellulose hydrogel, in experimental study ${ }^{1}$
}

\author{
Elísio Rodrigues Coelho Junior, Laura Olinda Bregieiro Fernandes Costa ${ }^{\mathrm{II}}$, Arinaldo Vasconcelos Alencar ${ }^{\mathrm{III}}$, Ana Paula \\ Guimarães Barbosa ${ }^{\mathrm{IV}}$, Flávia Crisina Morone Pintov ${ }^{\mathrm{V}}$, José Lamartine de Andrade Aguiar ${ }^{\mathrm{VI}}$
}

\author{
DOI: http://dx.doi.org/10.1590/S0102-865020150030000005
}

IFellow PhD degree, Postgraduate Program in Surgery, Federal University of Pernambuco (UFPE), Recife-PE, Brazil. Conception and design of the study, surgical procedures, acquisition and interpretation of data, manuscript writing.

IIAssistant Professor, College of Medical Sciences of Pernambuco, Department Maternal Child, State University of Pernambuco (UPE), Recife-PE, Brazil. Technical procedures, acquisition of data.

IIIAssociated Professor, Faculty of Medical Sciences of Pernambuco, Center for Integrated Health Amaury de Medeiros, UPE, Recife-PE, Brazil. Technical procedures.

${ }^{\text {IV } M e d i c a l ~ A s s i s t a n t, ~ D e p a r t m e n t ~ o f ~ G y n e c o l o g y ~ a n d ~ O b s t e t r i c s, ~ I n s t i t u t e ~ o f ~ I n t e g r a t i v e ~ M e d i c i n e ~ P r o f e s s o r ~ F e r n a n d o ~ F i g u e i r a ~(I M I P), ~ R e c i f e-P E, ~}$ Brazil. Technical procedures.

vAssistant Professor and Researcher for Experimental Surgery, Department of Surgery, Center for Health Sciences, UFPE, Recife-PE, Brazil. Statistical analysis, interpretation of data, critical revision.

${ }^{\mathrm{VI}}$ Associate Professor, Postgraduate Program in Surgery, Department of Surgery, UFPE, Recife-PE, Brazil. Intellectual and scientific content of the study, critical revision.

\section{ABSTRACT}

PURPOSE: To analyze the effectiveness of bacterial cellulose hydrogel as a barrier in preventing postoperative peritoneal adhesion in rat model.

METHODS: Experimental study with 45 Wistar rats (Rattus norvegicus) that were divided into three groups for the following treatments: A. Saline, B. Oxidized Regenerated Cellulose (ORC) barrier, and C Bacterial Cellulose Hydrogel (BCH) barrier. After 45 days of the surgery the adhesions were classified and graded according to the qualitative score. The histological parameters were evaluated using a modified semi-quantitative scale to rate the extent of fibrosis, inflammatory reaction and vascular proliferation.

RESULTS: Compared with the saline group (A), the treatments with ORC barrier (B) and BHC barrier (C) resulted in a smaller number of adhesions ( $\mathrm{p}=0.019$ and $\mathrm{p}=0.003$ on Fisher's exact test, respectively). Data from inflammation and neovascularization showed no statistically significant difference between the groups BHC and ORC ( $\mathrm{p}=0.426$ and 0.446 on chi-square test, respectively).

CONCLUSION: Bacterial cellulose hydrogel is effective as a bio-re-absorbable barrier for preventing postoperative peritoneal adhesions. Key words: Cell Adhesion. Hydrogel. Animal Experimentation. Rats. 


\section{Introduction}

Adhesions are a frequent postoperative complication that may result in small-bowel obstruction, infertility, chronic abdominal pain, and high risk of complications in a second operation. However, the formation of adhesions continues to pose a challenge and is a major cause of morbidity and mortality rates ${ }^{1}$.

Both general surgeons and gynecologists ${ }^{2}$ are involved in increasing knowledge of the pathophysiology and the study of new mechanisms of adhesion prevention. Towards this, we evaluated different mechanical barriers as an efficient method for preventing postoperative intra-abdominal adhesions and reduce their complications ${ }^{3}$. Significant advances have been made in surgical techniques for preventing adhesions and in the development of products to prevent adhesion ${ }^{4}$.

To prevent peritoneal adhesion, we used a bacterial cellulose hydrogel $(\mathrm{BCH}), 0.8 \%$ cellulose in $99.2 \%$ water as a mechanical barrier. This bacterial cellulose ${ }^{5}$ has been previously used with satisfactory results in various areas of experimental surgery such as in the scarring of cutaneous wounds ${ }^{6}$ dressing used after hypospadias surgery ${ }^{7}$, as well as in the grafting used in vascular surgery ${ }^{8,9}$. The biocompatibility of the bacterial cellulose suggests that it does not induce inflammatory reaction and might be used as a sealant to prevent adhesions following gynecological and abdominal surgery.

The mechanical separation of the peritoneal surfaces of the pelvic organs plays an important role in the post-operative scarring process and in reducing the risk of future adhesions ${ }^{10}$. Liquid and solid barriers are used to prevent post-operative adhesions $^{11-14}$.

The aim of this study was to evaluate the protection effect of the bacterial cellulose hydrogel (BCH) as a mechanical barrier to reduce inflammatory reactions, fibrosis and the adhesion formation in the intra-abdominal structures after surgical incision on the uterine horn of rats, comparing the results with the use of an oxidized regenerated cellulose (ORC) barrier and using a saline group.

\section{Methods}

This research was approved by the Institutional Animal Bioethics Committee of the Center Biological Sciences of UFPE, protocol number: 23076.027396/2009.09, December, 14, 2011.

Forty-five female Wistar rats (Rattus norvegicus albinus), age 180 days. The rats were randomly allocated into three groups of 15 animals: A. saline, B. Oxidized Regenerated Cellulose ORC barrier, and C. Bacterial Cellulose Hydrogel - $\mathrm{BCH}$ barrier.
They were housed with cycles of night and day with standard food and water ad libitum.

The surgical procedure was carried out under anesthesia with the intramuscular application of ketamine chloral hydrate $(5 \mathrm{mg} / 100 \mathrm{~g}$ of body weight) and xylazine chloral hydrate $(2 \mathrm{mg} / 100 \mathrm{~g}$ of body weight). Intramuscular atropine sulfate was used as a pre-anesthetic $(0.44 \mathrm{mg} / \mathrm{kg})$.

\section{Synthesis of bacterial cellulose hydrogel}

Bacterial cellulose hydrogel $(\mathrm{BCH})$ was produced from sugars of sugar cane in the laboratory of biopolymers at the Experimental Station of Sugarcane, Federal Rural University of Pernambuco, Brazil ${ }^{5}$. The hydrogel was obtained by hydration of microcrystalline bacterial cellulose at a ratio of $0.8 \%$ cellulose in $99.2 \%$ water and sterilization by gamma ray.

\section{Surgical procedure: induction of adhesions and evaluation}

The uterine horns were exposed and a $1.5 \mathrm{~cm}$ linear incision was made by electro-cautery on the anterior surface of the left horn. Hemorrhage points were coagulated, and the incision was closed with Prolene 7-0 in continuous stitches.

The wound was then covered with a barrier of ORC film, or $5 \mathrm{~mL}$ of saline, or hydrogel of bacterial cellulose according to the respective group. The abdominal wall was closed using continuous prolene 5.0 fascia sutures and the skin was closed with Nylon 5.0 thread $\left(\right.$ Mononylon $\left.^{\circledR}\right)$. Antibiotic prophylaxis was not provided and the animals were checked daily for complications control.

On the 45th day after surgery, the rats were anesthetized in the same way and a U-shaped abdominal incision was used to approach the peritoneal cavity to investigate the formation and intensity of adhesions.

The peritoneal cavity was photographed using a Sony ${ }^{\circledR}$ DSC - s650 camera fixed at a standard distance. Photos were used for later analysis of the extent of site-specific adhesions using AutoCAD. The operated segment of the uterus was then removed and fixed in 10\% formaldehyde for histological analysis. The animals were euthanized by an overdose of sodium thiopental.

\section{Assessment of adhesion formation}

The adhesion score was graded according to the qualitative numeric system developed by Wallwiener et al. ${ }^{15}$ from 0 (absent) 
to 3 (very severe), where 0 and 1 represent adhesions that are not clinically significant, whereas grade 2 and 3 adhesions may give rise to obstruction of the intestines. For the purpose of analysis, these ratings were further grouped as severe (2-3) or slight (0-1).

\section{Histological evaluation}

Slices of four micrometers of the segment of the uterus were colored with H\&E and Masson's trichrome. These histological preparations were evaluated using a modified semiquantitative scale (0-3), the extent of fibrosis, the inflammatory reaction and vascular proliferation ${ }^{16}$.

\section{Statistical analysis}

The normality of variables was confirmed using the Kolmogorov-Smirnov normality test. Fisher's Test was used to compare qualitative variables. Parametric (ANOVA) and nonparametric (Kruskal-Wallis) methods were used for comparisons of qualitative variables. Multiple comparisons were carried out using Tamhane's T2 test (ANOVA Post Hoc Tests). The GraphPad Prism 4.0 software was used for statistical analysis. The significance level for rejecting the null hypothesis was $5 \%(\mathrm{p} \leq 0.05)$.

\section{Results}

The animals responded well to the surgical procedure. One rat in the saline group died immediately after surgery, probably due to an anesthetic complication. Bodyweight changes followed a similar course in the various groups in all three experiments.

The number of animals with adhesion, severity of adhesion and absolute cross-sectional areas of adhesions were evaluated in groups A - Saline, B - ORC and C - BCH. They are shown in Table 1.

The severity of peritoneal adhesions (\%) in groups B and $\mathrm{C}$ showed a statistically significant difference compared to group $\mathrm{A}(\mathrm{p}=0.019$ and 0.003 respectively). Between the groups B and C there was no statistically significant difference ( $p=0.4621$, Fisher's Test). The comparison of the area of adhesions using Tamhane's $\mathrm{T} 2$ test, revealed that there was a significant difference between the means for groups $B(p<0.001)$ and $C(p<0.001)$ when compared with group A (Table 1).

Relative to inflammatory reaction and vascular proliferation, there was no statistically significant difference between the groups ( $\mathrm{p}=0.426$ and 0.446 , respectively). Histopathological study of all cases did not reveal ORC or $\mathrm{BCH}$ residue in the peritoneal cavity.

TABLE 1 - Severity of adhesion per group.

\begin{tabular}{lccccccc}
\hline Groups & $\mathbf{N}$ & $\begin{array}{c}\text { With } \\
\text { adhesions }\end{array}$ & $\begin{array}{c}\text { \% with } \\
\text { adhesions }\end{array}$ & $\begin{array}{c}\text { With severe } \\
\text { adhesions }\end{array}$ & $\begin{array}{c}\text { \% with severe } \\
\text { adhesions }\end{array}$ & $\begin{array}{c}\text { Multidimensional } \\
\text { Adhesion Score }\end{array}$ & $\begin{array}{c}\text { Adhesions } \\
\text { (cm2) }\end{array}$ \\
\hline Saline & 14 & 14 & 100 & 11 & 78.57 & $8.07 \pm 2.84$ \\
ORC & 15 & 10 & $66,7^{\text {a }}$ & 5 & $33.33^{\text {a }}$ & $3.27 \pm 2.82^{\text {a }}$ \\
BCH & 15 & 7 & $46,7^{\text {a }}$ & 3 & $20.00^{\text {a }}$ & $2.00 \pm 2.45^{\text {a }}$ & $0.37 \pm 0.32^{\text {a }}$ \\
\hline
\end{tabular}

Note: Values represent mean \pm SD. p $>0.05$. a fgroup A (saline). ORC, Oxidized Regenerated Cellulose; BCH, Bacterial Cellulose Hydrogel.

\section{Discussion}

Previous work has shown that, in combination with a good surgical technique, the ORC absorbable barrier prevents severe adhesions in $61 \%$ of cases and is twice as effective as surgery carried out without the use of anti-adhesion agents ${ }^{17}$ After laparoscopic surgery for ovarian cysts, $47 \%$ of the patients in whom this barrier was used were free of adhesions, compared to $25 \%$ in the control groups ${ }^{18}$. ORC is the anti-adhesion barrier that has been used for a long time in randomized clinical trials as the product that reduces the degree of adhesion severity. In controlled clinical studies and meta-analyses, the ORC absorbable barrier after open and laparoscopic surgery has been shown to be an effective anti-adhesive both for the first manifestation and recurrence of adhesions ${ }^{19,20}$.

Thus this product was chosen to serve as the standard for comparison with $\mathrm{BCH}$. Our results show that the use of ORC prevented the formation of severe adhesions in $66.67 \%$ of the rats; the $\mathrm{BCH}$ in $80 \%$ of the rats.

In this study, a multidimensional score was used, the percentage of animals free of adhesions, type, tenacity and extent of adhesions to determine the effectiveness of $\mathrm{ORC}$ and $\mathrm{BCH}$ as a barrier in comparison with a saline group. The experiments showed that the formation of adhesions was significantly lower in animals treated with ORC or $\mathrm{BCH}$ compared to those treated with saline. Despite the fact that bacterial cellulose hydrogel demonstrated an effective result, it failed to demonstrate statistical superiority over ORC (Table 1). 
Histological evaluation showed that there exists a relation between fibrosis and the treatment groups. In the case of inflammatory reaction and vascular proliferation, there was no statistically significant difference between these groups $(\mathrm{p}=0.426$ and 0.446 , respectively). The hydrogel did not induce specific inflammatory reactions, causing a lower fibrotic response compared to the non-treatment and ORC barrier groups. The effectiveness of the $\mathrm{BCH}$ may be due to the various particularities of this material, especially its high tolerance and adequate persistence in the peritoneal cavity during scarring.

Bacterial cellulose hydrogel may be an alternative way of preventing adhesions. $\mathrm{BCH}$ stays for an adequate time in the peritoneal cavity as a protective barrier, as it is made up of sugars. Other devices based on bacterial cellulose, raw material of the hydrogel, have already been used and shown to be effective in other areas of medicine in experimental studies involving animals ${ }^{6-9}$.

The high viscosity of bacterial cellulose hydrogel allows it to slip on the organs and spaces of the peritoneal cavity to form a thin layer on the visceral and parietal peritoneum. Different from solid products such as films, $\mathrm{BCH}$ can be molded into different shapes to fit different spaces in specific clinical situations.

In this study, after 45 days, the hydrogel was biodegraded and $\mathrm{BCH}$ residue was no longer found in the peritoneal cavity. This versatility gives it reach both on smooth and convex tissue surfaces, enabling it to be used in a wide variety of surgical scenarios.

\section{Conclusion}

Bacterial cellulose hydrogel is effective as a bio-reabsorbable barrier and is capable of preventing postoperative peritoneal adhesions in rat model.

\section{References}

1. Rajab TK, Wallwiener M, Talukdar S, Kraemer B. Adhesion-related complications are common, but rarely discussed in preoperative consent: a multicenter study. World J Surg. 2009;33(4):748-50. doi: 10.1007/s00268-008-9917-x.

2. Arung W, Meurisse M, Detry O. Pathophysiology and prevention of postoperative peritoneal adhesions. World J Gastroenterol. 2011;17(41):4545-53. doi: 10.3748/wjg.v17.i41.4545.

3. Ersoy E, Ozturk V, Yazgan A, Ozdogan M, Gundogdu H. Comparison of the two types of bioresorbable barriers to prevent intra-abdominal adhesions in rats. J Gastrointest Surg. 2009;13:282-86. doi: 10.1007/ s11605-008-0678-5.

4. Ten Broek RP, Stommel MW, Strik C, van Laarhoven CJ, Keus F, van Goor H. Benefits and harms of adhesion barriers for abdominal surgery: a systematic review and meta-analysis. Lancet. 2014;383(9911):48-59. doi: 10.1016/S0140-6736(13)61687-6.
5. Paterson-Beedlea M, Kennedya JF, Melob FAD, Lloyda LL, Medeirosb V. A cellulosic exopolysaccharide produced from sugarcane molasses by a Zoogloea $s p$. Carbohydrate Polymers. 2000;42(4):375-83. doi: 10.1016/S0140-6736(13)61687-6.

6. Coelho MCDOC, Carrazoni PG, Monteiro VLC, Melo FAD, Mota RA, Tenório Filho F. Biopolímero produzido a partir da cana-de-açúcar para cicatrização cutânea. Acta Cir Bras. 2002;17(suppl.1):11-3. doi: 10.1590/S0102-86502002000700003.

7. Martins AGS, Lima SVC, Araujo LAP, Vilar FO, Cavalcante NTP. A wet dressing for hypospadias surgery. Int Braz J Urol. 2013;39(3):408-13. doi: 10.1590/S1677-5538.IBJU.2013.03.15.

8.. Aguiar JL, Lins EM, Marques SR, Coelho AR, Rossiter Rde O, Melo RJ. Sugarcane biopolymer patch in femoral artery angioplasty on dogs. Acta Cir Bras. 2007;22 (Suppl. 1):77-81. doi: 10.1590/S010286502007000700015.

9. De Barros-Marques SR, Marques-Lins E, de Albuquerque MC, de Andrade-Aguiar JL. Sugarcane biopolymer patch in femoral vein angioplasty on dogs. J Vasc Surg. 2012;55(2):517-21. doi: 10.1016/j. jvs.2011.05.047.

10. Hellebrekers, BW, Trimbos-Kemper GCM, van Blitterswijk CA, Bakkum EA, Trimbos JBMZ. Effects of five different barrier materials on postsurgical adhesion formation in the rat. Hum Reprod. 2000;15(6):1358-63. doi: 10.1093/humrep/15.6.1358.

11. Menzies D, Pascual MH, Walz MK, Duron JJ, Tonelli F, Crowe A, Knight A. Use of icodextrin $4 \%$ solution in the prevention of adhesion formation following general surgery: from the multicentre ARIEL Registry. Ann R Coll Surg Engl. 2006;88(4):375-82. doi: 10.1308/003588406X114730.

12. Chaturvedi AA, Lomme RMLM, Hendriks $\mathrm{T}$, van Goor $\mathrm{H}$. Prevention of postsurgical adhesions using an ultrapure alginatebased gel. Br J Surg. 2013;100: 904-10. doi: 10.1002/bjs.9131.

13. Mettler L, Audebert A, Lehmann-Willenbrock E, Schive K, Jacobs VR. Prospective clinical trial of SprayGel as a barrier to adhesion formation: an interim analysis. J Am Assoc Gynecol Laparosc. 2003;10(3):339-44. PMID: 14567808.

14. Mais V, Ajossa S, Piras B, Guerriero S, Marongiu D, Melis GB. Prevention of de-novo adhesion formation after laparoscopic myomectomy: a randomized trial to evaluate the effectiveness of an oxidized regenerated cellulose absorbable barrier. Hum Reprod. 1995;10(12):3133-5. PMID: 8822429.

15. Wallwiener D, Meyer A, Bastert G. Adhesion formation of the parietal and visceral peritoneum: an explanation for the controversy on the use of autologous and alloplastic barriers? Fertil Steril. 1998;69(1):132-7. doi: 10.1016/S0015-0282(97)00429-9.

16. Irkorucu O, Ferahköşe Z, Memiş L, Ekinci O, Akin M. Reduction of postsurgical adhesions in a rat model: a comparative study. Clinics (Sao Paulo). 2009;64(2):143-8. doi: 10.1590/S1807-59322009000200012.

17. Azziz R. Microsurgery alone or with INTERCEED Absorbable Adhesion Barrier for pelvic sidewall adhesion re-formation. The INTERCEED (TC7) Adhesion Barrier Study Group II. Surg Gynecol Obstet. 1993;177(2):135-9. PMID: 8342092.

18. Franklin RR. Reduction of ovarian adhesions by the use of Interceed. Ovarian adhesion study group. Obstet Gynecol. 1995;86(3):335-40. PMID: 7651638 .

19. Sekiba K. Use of Interceed (TC7) absorbable adhesion barrier to reduce postoperative adhesion reformation in infertility and endometriosis surgery. The Obstetrics and Gynecology Adhesion Prevention Committee. Obstet Gynecol. 1992;79(4):518-22. PMID: 1553169.

20. Wiseman DM, Trout JR, Franklin RR, Diamond MP. Metaanalysis of the safety and efficacy of an adhesion barrier (Interceed TC7) in laparotomy. J Reprod Med. 1999;44(4):325-31. PMID: 10319300. 
ER Coelho Junior et al.

\section{Acknowledgement}

To Laboratory of Immunopathology Keizo Asami (LIKA), Federal University of Pernambuco.

To Sidney Pratt, native speaker that revised the English version of this text, Canadian, BA, MAT (The Johns Hopkins University), RSA diploma (TEFL).

\section{Correspondence:}

Flávia Crisina Morone Pinto

Núcleo de Cirurgia Experimental (NCE)

Av. Prof. Moraes Rego, 1235

50670-901 Recife-PE Brasil

Tel.: (55 81)2126-8562

fcmorone@gmail.com

Received: Nov 18, 2014

Review: Jan 20, 2015

Accepted: Feb 16, 2015

Conflict of interest: none

Financial sources: Federal Government (Ministry of Science and Technology, MCT): FINEP (Studies and Projects Financing Agency) and National Council for Scientific and Technological Development (CNPq)

${ }^{1}$ Research performed at Center for Experimental Surgery, Federal University of Pernambuco (UFPE), Recife-PE, Brazil. Part of PhD degree thesis, Postgraduate Program in Surgery, UFPE. Tutor: Prof. Dr. José Lamartine de Andrade Aguiar. 